\title{
Pengaruh Social Media Marketing melalui Platform Whatsapp pada Minat Beli Masyarakat
}

\author{
Soltan Takdir ${ }^{\otimes_{1}}$, Defran Siska ${ }^{\mathbf{2}}$ Rivandi $^{3}$ \\ 1,2,3 Universitas Amal Ilmiah Yapis Wamena \\ DOI : https://doi.org/10.37531/ecotal.v3i1.115
}

\begin{abstract}
Penelitian ini bertujuan menganalisis pengaruh Media Social Media Marketing Melalui Platform Whatsapp terhadap Minat Beli Masyarakat pada group Wamena Foods Goods Meals. metode penelitian yang digunakan yaitu metode kuantitatif asosiatif. Adapun populasi pada penelitian sebanyak 256 orang. Penentuan jumlah sampel menggunakan teknik purposive sampling yaitu dilakukansehingga diperoleh 72 orang sebagai sampel penelitian. Metode analisis yang digunakan yaitu metode deskriptif, analsisi regresi linier Sederhana, Pengujian hipotesi uji T dan Koefisien determinasi. Hasil penelitian menunjukkan bahwa Variabel media social marketing secara positif tetapi tidak signifikan mempengaruhi minat beli masyarakat.

Keywords : Social Media Marketing, media whatsapp, Minat Beli Masyarakat.
\end{abstract}

Corresponding Author :

E-mail address: soltantakdir@unaim-wamena.ac.id (Kabupaten JayawijayaBugi Hetuma Wamena, Hetuma,Papua)

“Received 08 December 2021, Accepted 12 January 2021, Published 24 January 2022” 


\section{Pendahuluan}

Era internet saat ini telah mewujudkan manusia sebagai global citizen, dimana interaksi manusia di dunia sudah tidak ada batas lagi. Interaksi manusia mampu menghadirkan pertemuan yang seolah nyata meski terdapat perbedaan ruang dan waktu. Interaksi manusia di era ini sangatlah dibantu oleh hadirnya media sosial yang ditawarkan melalui perangkat smarthphone untuk memudahkan akses internet. Hasil survei We Are Social yang dilakukan di Singapura pada 2017 menunjukkan bahwa penduduk Indonesia yang menggunakan media sosial mencapai 106 juta dari total populasi 262 juta. Aktivitas tertinggi pengguna media sosial di Indonesia dilakukan oleh para digital native dengan persentase $62 \%$ menggunakan smartphone, 16\% menggunakan komputer, dan 6\% menggunakan tab.(Triastuti, Endah, Dimas Adrianto, 2017).

Bagi individu, motivasi menggunakan media sosial adalah mencari informasi, berbagi informasi, hiburan, relaksasi, dan interaksi sosial . Bagi informasi atau perusahaan, media sosial banyak digunakan sebagai media atau alat untuk melakukan komunikasi pemasaran. Tidak seperti media tradisional yang hanya menerapkan komunikasi satu arah, media sosial mampu menerapkan komunikasi dua arah atau lebih. Menggunakan media sosial sebagai alat komunikasi pemasaran tidak hanya seperti menggunakan internet dan teknologi, akan tetapi harus menggunakan taktik dan strategi komunikasi. (Whiting dan Williams, 2013, Wigmo, J., \& Wikström, E. ,2010.).

Dengan menggunkan kapabilitas media sosial dengan optimal, dapat diraih hasil yang ditargetkan dengan maksimal. Sangat penting mengetahui dengan mendalam kapabilitas media sosial sebagai alat komunikasi pemasaran, kemampuan apa saja yang media sosial miliki sebagai alat pemasaran, serta hasil apa saja yang dapat dicapai jika menggunkan media sosial sebagai alat pemasaran. Banyak penelitian telah dilakukan pada social media marketing diantaranya pengaruh social media marketing melalui instagram terhadap minat beli konsumen sugar tribe adalah 56\% berdasarkan hasil pengujian hipotesis secara parsial, didapatkan sub variable context, communication, dan connection memiliki pengaruh yang signifikan terhadap minat beli, sedangkan sub variable $\neg$-collaboration tidak berpengaruh signifikan terhadap minat beli (Arief \& Millianyani, 2015), penelitian lain juga menunjukkan hubungan yang rendah tetapi pasti antara strategi pemasaran Brodo Footwear melalui media instagram dan minat beli (Kurniawati \& Arifin, 2015), dalam penelitian ini melihat dari social media marketing melalui whatsapp terhadap minat beli suatu produk. 
Soltan Takdir ${ }^{凶}$, Defran Siska ${ }^{2}$ Rivandi $^{3}$

Wamena merupakan salah satu kota di Indonesia yang memiliki perkembangan yang cukup signifikan dalam bidang industri makanan. Perkembangan kuliner di kota wamena saat ini sedang mengalami kemajuan yang cukup pesat. Hal tersebut terlihat dari banyaknya perusahaanperusahaan yang bergerak dibidang kuliner dari skala kecil, menengah, sampai besar.

Tabel 1.Jumlah perintisan usaha baru dan perpanjangan surat izin usaha Kabupaten Jayawijaya

Tahun Jumlah

\begin{tabular}{cc}
\hline $\mathbf{2 0 1 8}$ & 684 \\
\hline $\mathbf{2 0 1 9}$ & 1264
\end{tabular}

Sumber Data : DPMK-PTSP Kabupaten Jayawijaya, 2021

Terdapat peningkatan yang cukup signifikan dalam perintisan dan perpanjangan surat izin usaha hal ini membuat persaingan bisnis khususnya dibidang kuliner kota Wamena sangat ketat sehingga pelaku bisnis harus memiliki strategi yang tepat untuk dapat bersaing. Pelaku bisnis dituntut untuk berinovasi dengan bisnisnya dengan mengikuti perkembangan atau trend agar lebih unggul dan memberikan kesan yang berbeda dari para pesaingnya, data tersebut cukup menjelaskan tentang tingginya minat beli masyarakat Wamena yang semakin tinggi. Sekarang ini banyak bermunculan bisnis yang memanfaatkan trend dengan menggunakan media sosial baik aplikasi Facebook, Instagram, Whatsapp dan lain-lain.

Gambar 1. Group Whatsapp Wamena Foods Goods Meals
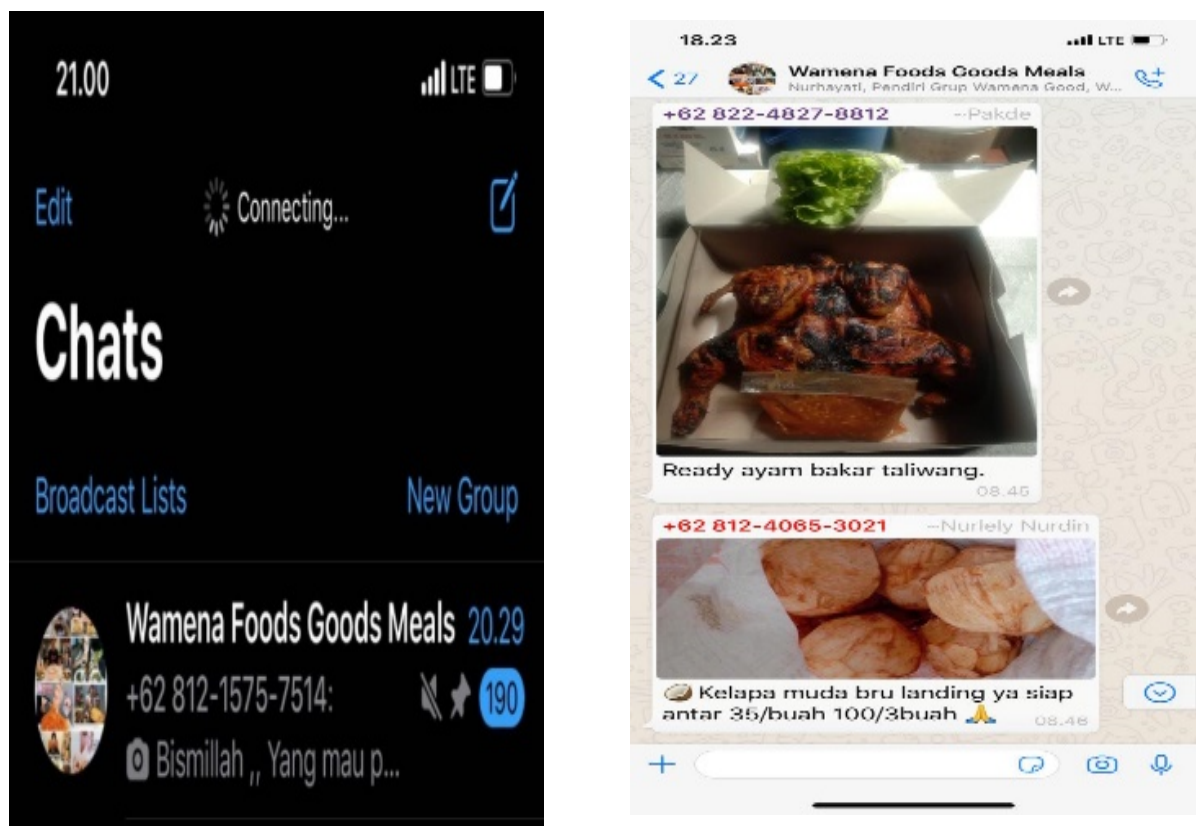

Sumber : Grup Whatsapp Wamena Foods Goods Meals, 2021 
Soltan Takdir ${ }^{凶}{ }_{1}$, Defran Siska ${ }^{2}$ Rivandi $^{3}$

Pengaruh Social Media Marketing melalui Platform Whatsapp......

DOI : https://doi.org/10.37531/ecotal.v3i1.115

Aplikasi Whatsapp sendiri memiliki keunggulan karena memiliki fitur grup yang dapat menampung hingga ratusan anggota untuk mempertemukan produsen dan konsumen dalam satu grup yang sama. Grup Whatsapp Wamena Foods Goods Meals ini telah dibentuk pada 01 Maret 2019 dengan jumlah anggota 256 peserta yang melaksanakan aktivitas bisnis sebagai produsen dan konsumen Dengan banyaknya produsen yang tergabung dalam grup Wamena Foods Goods Meals maka hal ini membuat persaingan antar produsen semakin ketat sehingga setiap produsen harus memiliki strategi yang tepat untuk dapat bersaing dalam menarik minat beli.

\section{Kajian Literatur}

\section{Social Media Marketing}

Menurut Nasrullah (2012) media sosial adalah medium di internet yang memungkinkan pengguna merepresentasikan dirinya maupun berinteraksi, bekerja sama, berbagi, berkomunikasi dengan pengguna lain, dan membentuk ikatan sosial secara visual. Menurut Hasan dalam Hannief dan Martini (2018) Social Media Marketing adalah sebuah kolaborasi massal, orkestra publik di dunia maya, yang pada hakikatnya saling memberi dan menerima informasi. Akar dari Social Media Marketing adalah melibatkan konsumen dalam sebuah percakapan maya yang saling memberikan nilai tambah buat kedua belah pihak, baik konsumen maupun produsen. Penggunaan sosial media yang berhubungan dengan aktivitas e-commerce, dimana perusahaan menginginkan perubahan dari "trying to sell" menjadi "making connection" dengan pelanggan. Menurut Chris heuer dalam Solis (2010) terdapat 4C dalam penggunaan social media marketing, yaitu 1)Context: "How we frame our stories". Adalah kita membentuk sebuah cerita atau pesan (informasi) seperti bentuk dari sebuah pesan itu sendiri, penggunaan bahasa maupun isi dari pesan tersebut. 2) Communication: "The parctice of sharing our sharing storty as well as listening, responding, and growing". Adalah berbagi cerita atau pesan (Informasi) sebaik kita mendengar, merespon, dan tumbuh dengan berbagai cara yang membuat pengguna merasa nyaman dan pesan tersampaikan dengan baik. 3) Collaboration: "Working together to make things better and more efficient and effective". Adalah bekerja sama untuk membuat segala hal menjadi lebih baik. Yaitu dengan kerja sama antara sebuah akun atau perusahaan dengan penggunaannya di media sosial untuk membuat hal baik lebih efektif dan lebih efisien.4) Connection: "The relationships we forge and maintain". Adalah memelihara hubungan yang terbina. Bisa melakukan sesuatu yang bersifat berkelanjutan sehingga pengguna merasa lebih dekat dengan perusahaan pengguna media sosial.

\section{Minat Beli}

Menurut Anoraga (2000), minat beli adalah proses pengambilan keputusan konsumen sebelum membeli suatu produk yang akan ditawarkan atau yang diperlukan oleh konsumen. Sedangkan Menurut Listyawati (2016) minat merupakan bentuk penerimaan akan suatu hubungan antara diri seseorang dengan sesuatu di luar dirinya, semakin kuat atau dekat hubungan tersebut maka semakin besar minat sehingga minat tidak dibawa dari lahir, melainkan diperoleh kemudian sebagai akibat rangsangan adanya suatu hal yang menarik. Pengukuran efektivitas komunikasi pemasaran dapat dilihat pada model respon konsumen akan promosi yang dilakukan perusahaan. Pengukuran efektivitas minat beli masyarakat dapat dilihat pada model AIDA respon konsumen 
akan promosi yang dilakukan perusahaan. Menurut Kotler dan Keller (2009) menjelaskan teori AIDA (Attention, Interest, Desire, and Action) merupakan suatu pesan pesan yang harus mendapatkan perhatian, menjadi ketertarikan, menjadi minat, dan mengambil tindakan.

\section{Metode Penelitian}

Jenis Penelitian yang dengan metode penelitian kuantitatif jenis asosiatif. Sehingga dalam penelitian ini menjelaskan hubungan sebab akibat (kausal) antara 2 (dua) variabel bebas (independent variable) yaitu variable social media marketing dengan indikator konteks (context), Komunikasi (communication), Kolaborasi (Collaboration), dan Koneksi (connection) terhadap variabel terikat (dependent variable) yaitu minat beli masyarakat dengan indikator perhatian (Attention), Menarik (interest), Keinginan (Desire), dan Tindakan (Action). Penelitian ini dilaksanakan pada salah satu group yang melakukan aktifitas bisnis di Kota Wamena yaitu group Wamena Foods Goods Meals.

Populasi merupakan keseluruhan dari objek pada suatu wilayah yang akan diteliti (Hamid \& Patra,2019), populasi dalam penelitian ini seluruh penjual /produsen dan pembeli / konsumen yang bergabung dalam grup Whatsapp Wamena Foods Goods Meals sebanyak 256 orang. Penentuan sampel dari populasi yang ada dilaksanakan secara subyektif (memilih) yang dapat dilakukan dengan pertimbangan bahwa peneliti telah mengetahui dengan baik informasi yang dibutuhkan dan dapat diperoleh dari seseorang atau kelompok sebanyak 72 orang.

Teknik pengumpulan data dilaksanakan dengan berbagai cara diantaranya dengan cara mengamati langsung dan pencatatan secara sistematis terhadap obyek peneltian. Daftar Pertanyaan (kuesioner), dan Dokumentasi dilakukan dengan cara pencatatan dari sejumlah dokumen (arsip) atau bukti - bukti lain yang terdapat pada lokasi penelitian yang dilaksanakan yang berhubungan dengan masalah yang diteliti. Instrument penelitian yang digunakan adalah dengan menggunakan skala likert dalam bentuk kuesioner pernyataan dengan rincian sangat setuju skor 5, setuju skor 4, ragu - ragu skor 3, tidak setuju skor 2 dan sangat tidak setuju skor 1 . Dalam menguji kualitas instrument penelitian dilakukan uji validitas dan realibilitas. 


\section{Hasil Penelitian dan Pembahasan}

\subsection{Hasil Uji Validitas dan Realibilitas}

Dalam uji validitas ini dilakukan pengujian atas butir - butir pertanyaan pada kuisioner dengan jalan menghitung koefisien korelasi Pearson dari tiap-tiap pertanyaan dengan skor total yang diperoleh. Selanjutnya dibandingkan dengan angka $r$ tabel dengan derajat kebebasan (0.05). Sehingga penjabaran tiap - tiap butir pernyataan pada kuesioner pada Variabel minat beli masyarakat $(Y)$ dengan 16 item pernyataan nilai rhitung berada pada rentang nilai 0,445 hingga 0,761. Pada variabel social media marketing (X) dengan 16 item pernyataan nilai rhitung berada pada rentang nilai 0,418 hingga 0.655 . Sehingga nilai rhitung lebih besar dari nilai rtabel $(0,2318)$ dan dapat disimpulkan seluruh item pernyataan pada tiap variabel dinyatakan valid.

Pengujian realibilitas dengan menggunakan nilai cronbach alpha, suatu variabel maupun konstruk dikatakan reliabel jika memberikan nilai croanbach's alpha $>0,60$. Berdasarkan hasil pengujian didapatkan nilai cronbach's alpha variabel minat beli masyarakat (Y) sebesar 0.750, dan variabel social media marketing $(X)$ sebesar 0.797, dimana semua nilai cronbach's alpha > 0.60 sehingga seluruh variabel yang digunakan reliabel untuk digunakan.

\section{Karakteristik Responden}

Berdasarkan hasil kuesioner yang telah dibagikan dapat menggambarkan berbagai kondisi yang ada pada lokasi penelitian diantaranya dari segi umur dimana dominan responden berada pada usia 26 - 30 tahun (33,3\%), yang berusia < 25 tahun sebesar 26,4\% dan 31 - 35 tahun sebesar $22,2 \%$, serta yang berusia $>35$ tahun sebesar 18,1\%. Pada segi tingkat pendidikan responden dominan pada tingkat pendidikan SMA/SMK sebesar 54,2\%, kemudian Sarjana sebesar 29,2\% dan paling sedikit responden berpendidikan SMP sebesar 16,6\%.

\section{Analisis Deskriptif}

Analisis Deskriptif digunakan untuk menjelaskan variabel berdasarkan hasil dari data. Analisis yang digunakan dengan menggunakan analisa persentase pada masing - masing variabel yang digunakan dengan menjelaskan pada indikatornya. Hasil pengukuran Deskripsi Variabel social media marketing $(\mathrm{X})$ pada tabel 2 berikut ini :

Tabel 2. Deskripsi Variabel Social Media marketing
Indikator
Data Jawaban Responden 
Soltan Takdir ${ }^{\bowtie}$, Defran Siska ${ }^{2}$ Rivandi $^{3}$

Pengaruh Social Media Marketing melalui Platform Whatsapp.....

DOI : https://doi.org/10.37531/ecotal.v3i1.115

\begin{tabular}{|c|c|c|c|c|c|c|c|c|c|c|}
\hline & \multicolumn{2}{|c|}{ SS } & \multicolumn{2}{|c|}{$\mathbf{S}$} & \multicolumn{2}{|c|}{ CS } & \multicolumn{2}{|c|}{ TS } & \multicolumn{2}{|c|}{ STS } \\
\hline & \multicolumn{10}{|c|}{ Rata - rata } \\
\hline & $\mathbf{F}$ & $\%$ & $\mathbf{F}$ & $\%$ & $\mathbf{F}$ & $\%$ & $\mathbf{F}$ & $\%$ & $\mathbf{F}$ & $\%$ \\
\hline 1. Konteks & 9,25 & 12,8 & 34,5 & 47,9 & 20 & 27,8 & 8 & 11,1 & 0,25 & 0,3 \\
\hline $\begin{array}{l}2 . \\
\text { Komunikasi }\end{array}$ & 11,5 & 16 & 39,75 & 55,2 & 18,25 & 25,3 & 2,5 & 3,5 & 0 & 0 \\
\hline 3. Kolaborasi & 12,75 & 17,7 & 41,25 & 57,3 & 16 & 22,2 & 2 & 2,8 & 0 & 0 \\
\hline 4. Koneksi & 11,5 & 16 & 45 & 62,5 & 15 & 20,8 & 0,5 & 0,7 & 0 & 0 \\
\hline Rata-rata & 11,25 & 15,63 & 40,13 & 55,73 & 17,31 & 24,03 & 3,25 & 4,53 & 0,06 & $\mathbf{0 , 0 8}$ \\
\hline
\end{tabular}

Sumber : Olahan data Primer, 2021

Dari hasil pengolahan data pada tabel 2. berdasarkan 4 Indikator jawaban rata-rata responden dapat dilihat bahwa pengukuran Variabel social media marketing (X)dengan empat Indikator diperoleh rata-rata responden paling banyak menjawab setuju yakni sebanyak 40,13 responden atau 55,73\% kemudian sebanyak 15,63\% menjawab sangat setuju yang menjawab cukup setuju sebanyak $24,3 \%$ dan yang menjawab tidak setuju 4,53\% serta yang menjawab sangat tidak setuju sebanyak 0,08\%. Sedangkan pada variabel Minat Beli Masyarakat terbagi dalam empat indikator yaitu : Perhatian, Menarik, Keinginan, dan Tindakan pada tabel 3.

Tabel 3. Deskripsi Variabel Social Media marketing

Indikator Data Jawaban Responden

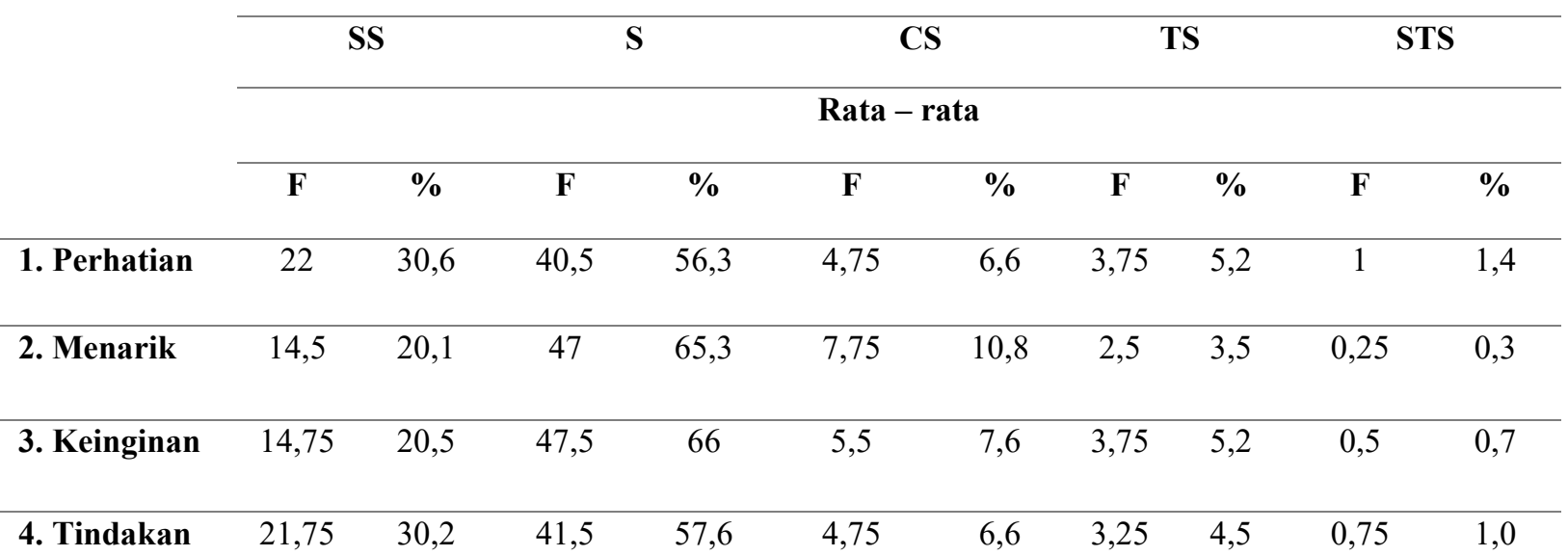


Soltan Takdir ${ }^{凶}{ }_{1}$, Defran Siska ${ }^{2}$ Rivandi $^{3}$

Pengaruh Social Media Marketing melalui Platform Whatsapp.....

DOI : https://doi.org/10.37531/ecotal.v3i1.115

$\begin{array}{lllllllllll}\text { Rata-rata } & 18,25 & 25,35 & 44,13 & 61,30 & 5,69 & 7,90 & 3,31 & 4,60 & 0,63 & 0,85\end{array}$

Sumber : Olahan Data Primer, 2021

Dari hasil pengolahan data diatas berdasarkan 4 Indikator jawaban rata-rata responden dapat dilihat bahwa pengukuran Variabel Minat Beli $(\mathrm{Y})$ dengan empat Indikator diperoleh rata-rata responden paling banyak menjawab setuju yakni sebanyak 44,13 responden atau $61,30 \%$ kemudian sebanyak 25,35\% menjawab sangat setuju yang menjawab cukup setuju sebanyak $7,90 \%$ dan yang menjawab tidak setuju $4,60 \%$ serta yang menjawab sangat tidak setuju sebanyak $0,85 \%$.

\subsection{Analisis Regeresi Linier}

Analisis regresi linier adalah hubungan secara linier antara satu independent $(\mathrm{X})$ dengan variabel dependen (Y). Karena nilai koefisien bernilai positif (+)maka dengan demikian dapat dikatakan bahwa social media marketing $(\mathrm{X})$ berpengaruh positif terhadap Minat Beli Masyarakat $(\mathrm{Y})$ dengan persamaan regresinya $Y=51,421+0,154 \mathrm{X}$. Angka koefisien regresi nilainya sebesar 0,154. angka ini mengandung arti bahwa setiap penambahan 1 tingkat social media marketing $(X)$ maka Minat Beli (Y) meningkat sebesar 0,154. Dengan nilai konstanta tetap sebesar 51,421.

\subsection{Pengujian Hipotesis Parsial (Uji T) dan Koefisien Determinasi}

Hipotesis penelitian yang diajukan terdiri atas 1 bagian yaitu $\mathrm{H} 1=$ social media marketing $(\mathrm{X})$ berpengaruh positif dan signifikan terhadap Minat Beli Masyarakat.

Dalam pengujian hipotesis tersebut menggunakan metode uji - $t$ dengan cara membandingkan antara ttabel dan thitung didapatkan nilai thitung pada variabel social media marketing sebesar 1,232 dan nilai ttabel pada $1=0,05$ untuk uji dua pihak didapatkan sebesar 1,997 sehingga thitung $(1,232)>$ ttabel $(1,997)$ serta nilai sig 0,222 > 0,05. Dengan demikian H1 diterima dan dapat disimpulkan social media marketing berpengaruh positif tetapi tidak signifikan terhadap minat beli masyarakat.

Dari hasil pengolahan data didapatkan Nilai koefisien determinasi sebesar 0,021 hal ini menunjukkan bahwa kontribusi variabel social media marketing pada perubahan Minat Beli Masyarakat sebesar 2,1\% sedangkan sisanya 97,9\% dipengaruhi oleh variabel lain diluar dari model analisis. 
Soltan Takdir ${ }^{凶}{ }_{1}$, Defran Siska ${ }^{2}$ Rivandi $^{3}$

Berdasarkan hasil pengujian yang telah dilakukan menunjukkan bahwa variabel social media marketing melalui media Whatsapp berpengaruh positif tetapi tidak signifikan terhadap peningkatan variabel minat beli masyarakat Hal tersebut diperkuat pada koefisien determinasi kontribusi variabel social media marketing melalui media whatsapp pada perubahan minat beli masyarakat sangat kecil hanya sebesar 2,1\% sedangkan variabel lainnya diluar dari model analisis sebesar sangat besar yaitu 97,9\%. Hal ini dimungkinkan terjadi social media marketing melalui media whatsapp yang belum maksimal sehingga tidak mempengaruhi secara signifikan pada minat beli masyarakat.

Jika dianalisis lebih jauh dapat kita uraikan dapat hasil deskripsi jawaban responden dimana didapatkan bahwa minat beli masyarakat pada indikator keinginan dan Tindakan yang masih sangat kecil, masyarakat hanya tertarik pada suatu produk yang ditawarkan melalui media whatsapp melalui indicator perhatian dan menarik. Hal ini bisa diakibatkan pada pemasaran produk masih terdapat kelemahan pada indicator konteks dan komunikasi yang tidak intens yang dilakukan kepada konsumen yang terdapat dalam group whatsapp tersebut.

Hasil penelitian ini sangat berbeda dengan penelitian yang dilakukan oleh Giri Maulana Arief dan Heppy Milliyani (2015) menunjukan bahwa pengaruh Social Media Marketing melalui Instagram terhadap Minat Beli adalah 56\%, begitupula penelitian yang dilakukan Dahmiri (2020) Ariesandy dan Zuliestiana. bahwa variabel social media marketing secara parsial berpengaruh signifikan terhadap variabel minat beli masyarakat. Walaupun jika melihat identitas responden dominan berumur 20-25 Tahun atau 26,4\% dan 26-30 Tahun atau 33,3\% dari keseluruhan responden dan dapat dikatakan usia tersebut paling aktif menggunakan media sosial. Namun, hal tersebut tidak menjadi sebuah ukuran untuk dikarenakan belum tumbuhnya kebiasaan masyarakat Wamena dalam hal jual beli online, tapi juga karena seringnya terjadi gangguan internet dikota Wamena yang juga menjadi salah satu faktor.

\section{Kesimpulan}

Berdasarkan hasil penelitian yang didapatkan, maka dapat ditarik kesimpulannya terdapat pengaruh postif tetapi tidak signifikan variabel social media marketing melalui whatsapp terhadap minat beli masyarakat pada group Wamena Foods Goods Meals. 


\section{References :}

Anoraga, Pandji., 2000, Manajemen Bisnis, Jakarta : PT Rineka Cipta

Arief, G. M., \& Millanyani, H. (2015). Pengaruh social media marketing melalui instagram terhadap minat beli konsumen sugar tribe. eProceedings of Management, 2(3).

Ariesandy, P., \& Zuliestiana, D. A. (2019). Pengaruh Social Media Marketing Melalui Instagram Terhadap Minat Beli Konsumen Ladyfameshop. eProceedings of Management, 6(2).

Dahmiri, D. (2020). Pengaruh Social Media Marketing Dan Brand Equity Terhadap Minat Beli. KINERJA: Jurnal Ekonomi dan Manajemen, 17(2), 194-201.

Endah, T., Dimas, A., \& Akmal, N. (2017). Kajian dampak penggunaan media sosial bagi anak dan remaja (Vol. 1, No. 1). Puskakom UI.

Hamid, R. S., \& Patra, I. K. (2019). PENGANTAR STATISTIKA UNTUK RISET BISNIS DAN EKONOMI Konsep Dasar dan Aplikasi SPSS versi 25. Banten: CV. AA. RIZKY.

Hannief, S. M., \& Martini, E. (2018). Pengaruh Social Media Marketing Instagram Terhadap Loyalitas Merek Konsumen Warunk Upnormal. eProceedings of Management, 5(1).

Kotler, P., \& Keller, K. L. (2009). Manajemen Pemasaran, Edisi 13. Jakarta: Erlangga, 14.

Kurniawati, D., \& Arifin, N. (2015). Strategi pemasaran melalui media sosial dan minat beli mahasiswa. JURNAL SIMBOLIKA: Research and Learning in Communication Study, $1(2)$.

Listyawati, I. H. (2016). Peran Penting Promosi dan Desain Produk Dalam Membangun Minat Beli Konsumen. Jurnal Bisnis, Manajemen, Dan Akuntansi, 3(1).

Nasrullah, R. (2012). Internet dan ruang publik virtual, sebuah refleksi atas teori ruang publik habermas. Komunikator, 4(01).

Solis, B. (2010). Engage: The complete guide for brands and businesses to build, cultivate, and measure success in the new web. John Wiley \& Sons.

Whiting, A., \& Williams, D. (2013). Why people use social media: a uses and gratifications approach. Qualitative market research: an international journal.

Wigmo, J., \& Wikström, E. (2010). Social media marketing: What role can social media play as a marketing tool?. 